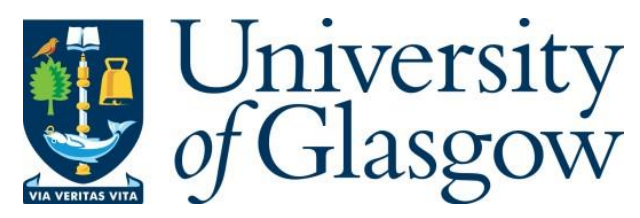

Swedlund, K. and Barr, M. (2021) The Gilmorehill Mystery: A Location-based Game for Campus Exploration. In: 20th IFIP International Conference on Entertainment Computing, Coimbra, Portugal, 02-05 Nov 2021, pp. 236-251. ISBN 9783030893934.

There may be differences between this version and the published version. You are advised to consult the publisher's version if you wish to cite from it.

http://eprints.gla.ac.uk/252341/

Deposited on: 20 September 2021

Enlighten - Research publications by members of the University of Glasgow http://eprints.gla.ac.uk 


\title{
The Gilmorehill Mystery: A Location-based Game for Campus Exploration
}

\author{
Kieran Swedlund ${ }^{1}$ and Matthew Barr ${ }^{2[0000-0002-5147-0673]}$ \\ 1 kieran.swedlund@gmail.com \\ 2 University of Glasgow Matthew.Barr@glasgow.ac.uk \\ https://www.gla.ac.uk/schools/computing/staff/matthewbarr/
}

\begin{abstract}
The University of Glasgow accommodates a large number of new students every year. Arriving at a new campus can seem daunting at first, as it is always a challenge to navigate a university's many buildings and pathways. Although in-person and self-guided online campus tours are currently offered by the University, in-person tours require advance booking and online tours do not provide the same level of immersion. As a solution, this paper describes the design, development and evaluation of an alternative: a location-based game for campus exploration. The prototype was evaluated remotely by eight participants in two stages, revealing technical issues that were subsequently addressed. A final, on-campus evaluation was carried out by a single participant using the final version of the game, with positive results. By utilizing player location tracking, this game successfully integrates a classic murder-mystery style story into a real-life setting-the University's campus-to provide an alternative means for new students to become familiar with their surroundings.
\end{abstract}

Keywords: Location-based game - Serious game - Augmented reality · Student experience $\cdot$ Higher education.

\section{Introduction}

This paper presents the design, development and evaluation of The Gilmorehill Mystery, a location-based mobile game aimed to encourage students to explore the University of Glasgow's campus.

Currently, the University offers two different forms of campus exploration guides: in-person group tours and self-guided online web tours. The first lets students reserve a time slot with experienced tour guides whereas the latter gives students a guided tour using a gallery of pictures and information on important buildings on the University's website. With the recent outbreak of COVID-19, in-person tours are not available to freshmen. Meanwhile, the self-guided aspect of the web based tour afford more freedom to explore the campus, however it does not feel very natural and immersive. Furthermore, is has been found that students introduced physically to a new campus retain more precise descriptions of the locations of the University's services [25].

The University welcomes thousands of new students every year, and it is essential to help integrate them into their new environment. Through orientation 
surveys, interviews, and focus groups, [9] found that often, during the first few weeks of university, new students feel lost and confused in regards to meeting new friends as well as being aware of different services and events the university offers. The University's campus is a large and complex historical site composed of over one hundred and fifty buildings, that can be overwhelming to new students.

It has also also been found that when integrating game mechanics into a campus exploration app, most students agreed that using the application meant they spent more time exploring the campus than planned [10]. The Gilmorehill Mystery is a mobile game that uses Augmented Reality (AR) to achieve the same motivational goal: to increase students' inclination to explore their campus.

\section{Background}

\subsection{Pervasive and Location-based Games}

Location-based games may be considered a sub-category of pervasive games. As the idea is relatively new, the exact definition of pervasive games is still under debate. However, [20] offers one explanation: "real-world games are augmented with computing functionality, or, depending on the perspective, purely virtual computer entertainment is brought back to the real world." This covers a broad range of games, where the level of digital integration ranges from minimal to fully digital. Location-based games have existed for twenty years, with the release of the first location-based game, BotFighters in the early 2000s [22]. Since then, this category of mobile games has become one of the most popular genres on the market, with successful games such as Pokemon GO and Ingress, developed by Niantic. Here, The Gilmorehill Mystery aims to combine the power of locationbased games with the benefits of serious games.

\subsection{Serious games}

Alongside being a location-based game with a full story line, the main aim of The Gilmorehill Mystery is to help students gain knowledge of the campus that they can later use to navigate it. This concept is described as 'learning by doing' [7]). Corti (2006, p. 1) describes serious games as being "all about leveraging the power of computer games to captivate and engage end-users for a specific purpose, such as to develop new knowledge and skills". Although this game does not teach explicit skills, but rather orientation and awareness, it still falls into this category. Corti notes that without an enticing gaming experience - featuring, for example, characters and rewards - there may be less incentive to participate in the learning experience. As a serious game, The Gilmorehill Mystery must motivate players to engage in exploring the campus when they may not initially be inclined to do so.

\subsection{Augmented Reality and learning}

In comparison to virtual reality, which requires a headset and other expensive equipment, AR can be as simple as an in-game map on a mobile device. [13] 
defines AR as "real-time direct or indirect view of a physical real-world environment that has been enhanced/augmented by adding virtual computer-generated information to it". AR has also been shown to help students obtain knowledge [14]. Specifically, it has been found that the use of AR in mobile discovery tools helps people understand more detailed information about an environment $[6$, 11]. The Gilmorehill Mystery aims to achieve this through strategically placed points of interest (POIs) that cover the most significant parts of campus, and a story line that guides users to each of these POIs.

[2] argue that the most important contextual information sources are location, environment, identity and time. Amongst these, location is considered paramount as "much other contextual information can be inferred from it". Focusing here on location, students can infer additional context such as where they are in relation to other objectives, or the true size and scale of their surroundings. They can discover new paths between POIs that can help them in the future when navigating those same areas on campus again.

\subsection{Related work}

Campus Explorer is a prototype mobile application that utilises game mechanics to entice students to engage more in campus life throughout the semester [4]. It adopts a location-based approach by tracking user location on an in-game map and implements mechanics such as social messaging boards, ongoing campus activities and building check-ins. Feedback from students was positive, with players preferring POI-based quizzes and puzzles. However, Campus Explorer is primarily an app with additional game features, rather than a full-fledged game.

Paperchase [16] is a mobile location-based game based on a traditional scavenger hunt style game. Player location is tracked using GPS, but the game does not represent puzzle locations as POIs on a map. Instead, players explore the campus by using the map to attempt to find hidden riddles. When found, corresponding multimedia is displayed, containing the answer to the riddle. This project was evaluated by first-year university students, and results showed that the riddles were enjoyed, especially in collaboration with other students. However, the riddles were not location-specific and were solved by observing embedded multimedia rather than player surroundings, thus decreasing the connection between player and real-world. Furthermore, Paperchase's main goal is to complete the hunt as fast as possible, which may run counter to the aim of becoming familiar with the university campus.

In 2016, Pokemon Go was named America's most popular mobile game ever, with over 500M downloads [19]. As such, Pokemon Go is a more recent example of how location-based games succeed in motivating players. Aside from its story and game mechanics, Pokemon Go offers extensive rewards, collaborative events and a well designed user interface. [23] found that one notable aspect of the game's appeal was increased observation and knowledge of players' surroundings, as it encouraged people explore unfamiliar points of interest. This suggests that a game story that fits the game design and structure may increase players' intrinsic motivation to explore. 
Building on such work, The Gilmorehill Mystery offers a way for students to familiarize themselves with buildings and services that will play a key role in their future university life, while playing an immersive location-based mobile game. This is accomplished by assigning puzzles to various in-game points of interest (POIs), associated with real locations on campus, that contribute to an overall murder-mystery story line. Playing the role of a detective, the player must piece together the mystery by visiting each location and thus explore areas with which they were not previously familiar. By linking in-game clues with the player's realworld location, students must analyse elements of their surroundings, such as campus buildings, to solve the puzzles. Although designed for the University of Glasgow campus, this project aims to illustrate the viability of a location-based game in the context of student engagement for all academic institutions.

\section{Design}

\subsection{Concept}

The main objective of the project is to encourage exploration of the University. This is achieved by having players navigate the campus buildings in real life [25]. Here, buildings are integrated into the game as marker-based POIs - a concept that is easily recognizable to anyone who has played a location-based game, such as Pokemon Go. Such markers are also found in most orientation apps that implement dynamic maps, such as Google Maps. To encourage players to visit POIs, a story-related puzzle was assigned to each, providing motivation for students to visit the building and discover that part of the campus. In order to increase immersion, the in-game POI tasks were associated with that real world location [18]. For example, an answer to one riddle is the name of a statue next to a building.

One challenge presented during the development of the game was the COVID19 lockdown and associated social distancing restrictions. In this context, it was decided that players were not to enter buildings, but only approach from a distance. For this to work, the POIs' GPS radius had to be expanded to avoid crowding and respect social distancing. GPS was favored over QR codes, as the latter require close contact with the POIs, which can result in unwanted crowding. Furthermore, scanning QR codes does not integrate well with a game story and might break the feeling of immersion for players.

With the target demographic being university students, the game story and challenges had to be appropriate to the context. Inspired by the previous successful use of riddles in a location-based game aimed at university students [16], the riddles and puzzles here were incorporated into an overall story. The University of Glasgow incorporates a myriad of architectural styles, dominated by the Gothic architecture of the main building. Such buildings invoke a feeling of mystery and darkness, and the idea of a murder-mystery themed game was thus proposed as a way to capitalize on this atmosphere. The game follows a roleplaying format, where the player takes on the role of a detective tasked with solving a murder case by interviewing in-game characters, located at specific 
real locations. Since most buildings on this campus are named after historical people, this was an effective way of tying the different locations together with the story.

\subsection{Story}

A story outline for The Gilmorehill Mystery was developed in the first instance, an excerpt of which is reproduced below.

You are an inspector from Scotland Yard who receives the case: The Gilmorehill Mystery. The current chair of Zoology, Sir John Stone, has disappeared and the Chief Superintendent suspects foul play on the campus. It is your job to solve the case! On arrival at the University of Glasgow's Main Gate entrance, you meet with the Chief Superintendent in charge of the case who explains the case $[\ldots]$

\subsection{Points of interest and Characters}

The buildings that would represent the in-game POIs needed to be placed in a way that would introduce the student to as much of the campus as possible. Once the locations were chosen, a game character and associated puzzle was assigned to that location. Paelke notes that constraints imposed by the physical world must be considered during the content authoring phase [24]. As such, it was ensured that each of the selected buildings was easily accessible, and all the POIs were visited to ensure that there were no major obstructions.

[5] emphasize the importance of immersion through their own location-based game Viking Ghost Hunter. Immersion can be deepened through narration but also by choosing appropriate locations that resonate with the theme and story of the game. Here, locations were primarily chosen based on their relevance to student life. In order to deepen the immersion, the selected buildings were all given a connection to the story [5]. This was achieved by introducing unique characters at each building, who furthered the detective's case when interrogated. Each POI was visited to find a geographical reference that would contribute to the overall story. For POIs that required a riddle answer, the area was scouted for any artwork or interesting landmarks that would contribute to finding the answer for that POI riddle.

\subsection{Puzzles}

As the game is based on player location, puzzles had to not only be integrated into the story line but also connect to the player's location as much as possible. Riddle-based puzzles were designed to challenge the player by giving them a georeferenced clue about a specific object in their surroundings. Having the riddle linked directly to their location not only creates an immersive gaming experience, but also encourages the player to engage in exploratory activities. Riddles are also linked to the game story, as they are integrated into objects found by the 
player throughout the game. For example, the sports building POI consists of finding the code to the professor's locker, the code being located on signs in front of the building. Each riddle is also accompanied by a hint and the possibility to reveal the answer. According to [26] adding hints extends interest. He also argues that the experience of joy when solving a puzzle is actually triggered by seeing the answer, not solving the actual puzzle, so providing this option is crucial.

\subsection{Player Motivation}

It was key for this game to have broad appeal. Yee's framework of player motivations is arguably the most widely-cited such framework [28], using empirical data to build upon and refine Bartle's more established player taxonomy [1]. Yee proposes a mix of motivational components that drive a player to play a game, rather than a single unique motivation, by showing a correlation exists between achievement, socializing and immersion. Yee's framework relates to the design of The Gilmorehill Mystery as follows:

- Achievement: players will get a sense of gratification from collecting map pieces and solving POI puzzles.

- Social: although social features are not explicit features of the game, the possibility for collaboration with other students at POIs provides opportunity for socializing.

- Immersion: Yee's framework indicates discovery and role-playing as subsets of this component. The geo-located POIs are designed to elicit a sense of discovery, while players assume the role of detective.

Map pieces are collected and shown as fragments of the larger map in order for the player to keep track of their progress. These pieces can only be found by completing the puzzles mentioned above. [26] describes this as the pyramid puzzle structure. This refers to a series of small puzzles that each give some kind of clue to a larger puzzle. Schell also states that such puzzles also extend interest, and thus, player motivation. A murder-mystery story adds to the seamless nature of the experience as detectives are synonymous with collecting clues and solving mysteries.

Here, the player is introduced to the task of collecting case information from POIs at the beginning of the game. Map pieces are located at a subset of the locations indicated across the map. In order to facilitate free exploration, map piece collection is implemented such that pieces can be collected in any order. [15] describe this as a "Jigsaw puzzle" approach, noting that stories tied to a geographical location "have a built-in quality for exploration in terms of finding the next piece".

\subsection{User Interface}

Good user interface (UI) design is key to a good gaming experience. [3] emphasizes the importance of UI in the context of immersion referring to it as 
"the key to that game's ability to present an immersive world making experience". The user interface is what connects the player to the virtual world of the location-based experience. A map-centric display showing the player's location at all times provides the connection between virtual and digital. POIs are displayed at all times, such that they may be used to navigate. The map is also a constant source of feedback on the system status as it shows player's location in relation to POIs. Nielsen [8] emphasizes the importance of keeping the user informed through constant feedback, which is achieved here by updating the player's in-game character location accordingly.

Nielsen outlines further important usability heuristics for UI design that should be followed to create an enjoyable UI experience. For example, the 'User control and freedom' heuristic addresses cases when the user triggers an interaction by accident. In such events, an "emergency exit" should be available for the player to opt out. Thus, all POI pop-ups triggered by either intentional or unintentional use of the system that appear in the UI should also be able to be closed by the player. Consistency is also key in designing a user interface, and is achieved by using the same style of display for all POI pop-ups and the same UI style for all character dialogues, as well as a consistent art work design among game elements and characters.

[3] also suggests that the UI should offer a balance between giving the user enough control to feel connected to the virtual world, and giving them so much control that they can 'break' the game. A minimalist UI design is appropriate for this. This aligns with Nielsen's 'Aesthetic and minimalist design' heuristic, where interfaces should not contain irrelevant data. By displaying only essential features and having the map take up most of the UI, the player is not always required to focus on the screen and thus adsorb more contextual information.

\section{Implementation and Evaluation}

The game was implemented using Unity [27] and the Mapbox SDK for Android [21]. Evaluation feedback was captured through surveys completed by all participants after playing through the prototype game. The first evaluation consisted of eight participants who played the game prototype from a remote location, via an emulated smartphone. For the second evaluation phase, the same eight participants experienced the full game. Furthermore, a field test evaluation was conducted at the University of Glasgow's campus in order to observe interaction with the system in its intended context.

In both stages, items based on playability heuristics relating to gameplay and usability were used for quantitative evaluation [17]. These were followed by more specific questions relating to the POIs and other game elements. Finally, qualitative feedback was gathered through open-ended questions allowing longer responses. Participants were invited to provide general feedback on the game, and make suggestions for future development iterations. With the exception of the on-campus field test, all evaluation data were collected by means of an online survey. 


\subsection{Stage One}

Prototype Implementation Here, the prototype game involved visiting three implemented POIs: the sports building, the Zoology building and the Library.

The main challenge with the evaluation of a location-based game during the COVID-19 lockdown was not being allowed to meet up and conduct extensive on-campus evaluations. Therefore, an alternative evaluation technique was used which required some adjustments to the code. The Mapbox SDK LocationProvider script provides several location tracking options, one being the EditorLocationArrayProvider, which takes mock location data in the form of an array and moves the in-game player accordingly. This provider is meant to be used in the Unity Editor for testing. By changing a few lines of code, it was possible to integrate the mock location data into the game on a participant's device. Participant devices could then use that location data instead of using the device's GPS.

This allowed players to remotely participate in the game evaluation, while experiencing most of the location-specific features of the game. Location data was implemented so that the game character would stop at a POI for three minutes, giving the user ample time to attempt and complete the puzzle. For the library journal search task, mock location data made the player move from the library POI to the journal POI to simulate walking. Since the puzzles included georeferenced riddles, another challenge was how to give players access to the clues in the areas surrounding the POI locations. To this end, players were provided with screenshots of the relevant location on Google Maps Street View.

\section{Results}

Quantitative Feedback Participants were presented with a Likert scale for each evaluation heuristic: 'Strongly Disagree', 'Disagree', 'Neutral' , 'Agree', 'Strongly Agree'. The first section concerned the evaluation of gameplay features (Fig 1). Overall, gameplay was well received by all users, with no participants choosing 'Disagree' or 'Strongly Disagree'. The most notable results where most participants 'Strongly Agreed' were for the "The game integrates well with the surroundings" (75\%) and "The game story supports the gameplay and is meaningful" $(75 \%)$ heuristics, indicating that the story was well-received and made sense in the game context.

The game supports different playing styles and There are no repetitive or boring tasks were the points participants felt most 'neutral' about. The first could be explained by the constraints of playing the game remotely. Having the game character walk a fixed route limits the gameplay possibilities for the participant, while the UI for each of the puzzles featured in the prototype was very similar.

The participants were then asked to rank a set of seven usability heuristics. Overall, results showed a mostly positive reaction. All participants agreed that 

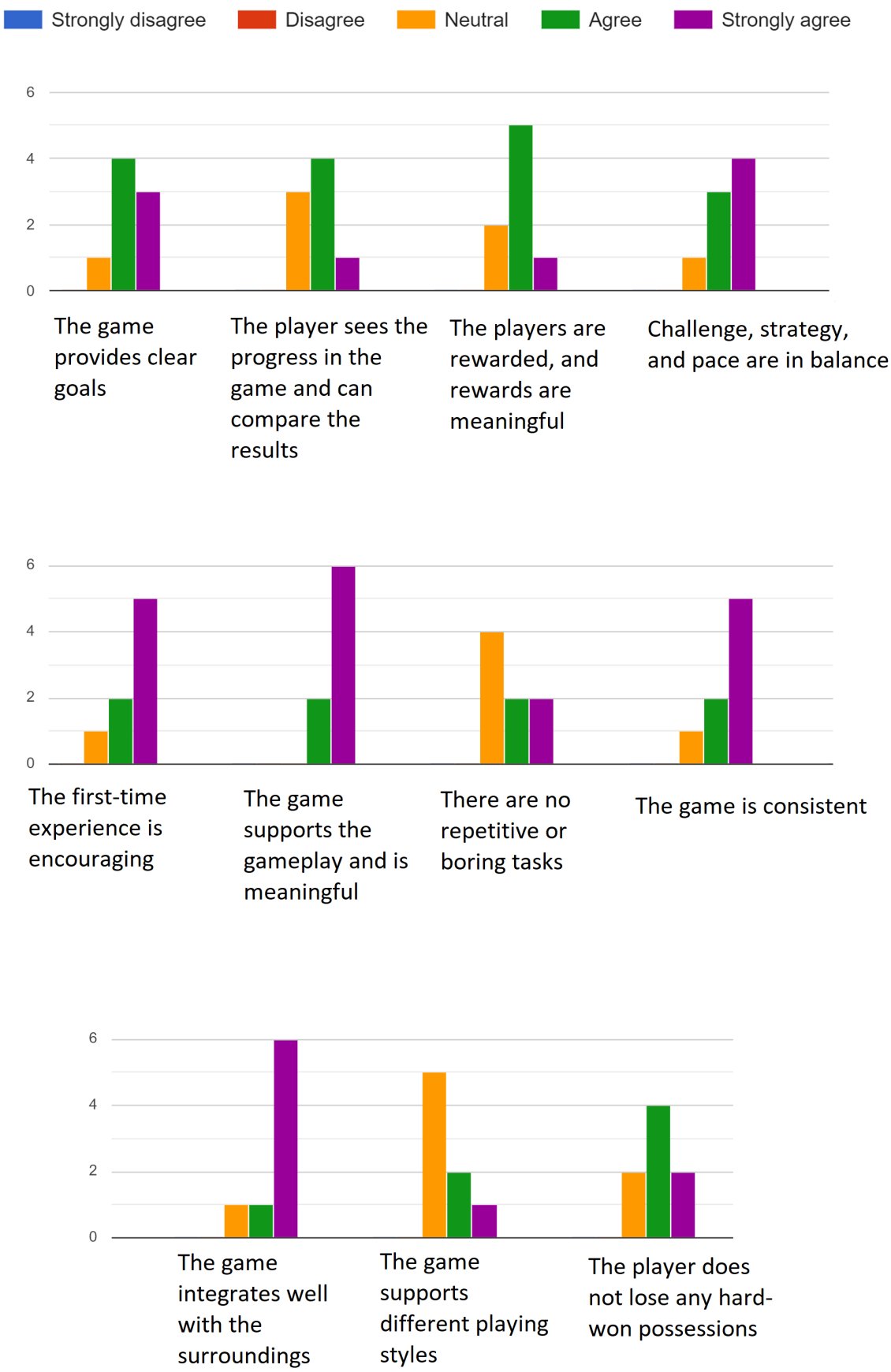

Fig. 1. Prototype gameplay evaluation results. 
the terminology was clear, that they did not have to memorize things unnecessarily, and that the game provided help. This was evidence of a successful UI design.

Three participants chose either 'Neutral' or 'Disagree' in response to The game gives feedback on the players actions. This can be linked to UI freezing due to lag issues mentioned by two participants. The prototype riddles also lacked feedback when play input was incorrect. Feedback for riddle inputs was implemented during the following development iteration.

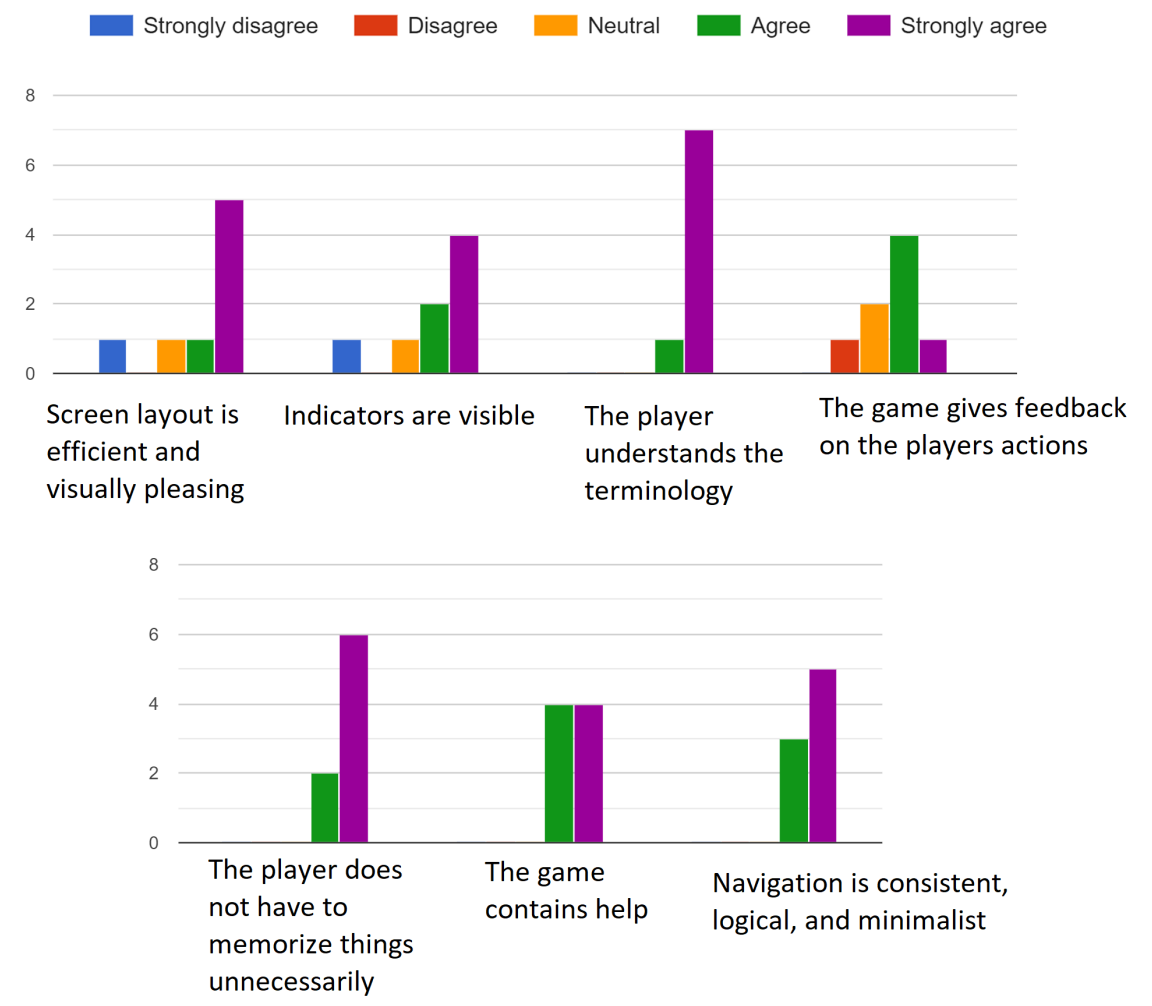

Fig. 2. Prototype usability evaluation results

When asked if the game would be useful for exploring specifically a University campus, $7 / 8$ participants $(87.5 \%)$ agreed. When asked about recommending it to a newcomer to the University, all participants agreed. In order to evaluate POI activity implementation, participants were also asked about their thoughts on the individual puzzles. They were given three response options: 'Too easy', 'Doable' and 'Too Hard'. In terms of levels of difficulty, the puzzles were considered 'Doable' with one participant choosing 'Too easy'. 
Participants were also asked to rank the enjoyability of the puzzles. Participants were given three options: 'Not Fun', 'OK, could be more fun (neutral)' and 'Fun'. Results for each puzzle ranged from $75 \%(6 / 8)$ to $37.5 \%(3 / 8)$ of participants rating them as 'Fun' with the remaining five being neutral. Participants were asked if they found the dialog interesting and helpful, with $100 \%$ agreeing it was useful.

Qualitative Feedback Participants were also asked to give longer responses in regards to the features implemented, and if their experience was enjoyable. In terms of additional features, players suggested the addition of music and a more interesting player character model. It was also clear that participants wanted a broader range of puzzles that were more playful in nature. However, there was evidence that players appreciated how well the game integrated with their surroundings: "The riddles are great, and I love the inclusion of locationspecific clues which are used to solve them - this will really work well with the format". This is useful to note, in light of the discussion of player motivation above, where both [26] and [15] highlight the importance of engaging puzzles in motivating players. Players were then asked to describe their overall experience. All gave positive affirmations in regards to their experience with a few pointing out technical shortcomings that they experienced, such as scaling issues and lag.

\section{$4.2 \quad$ Stage 2}

The second evaluation consisted of the fully implemented game. Since the prototype evaluated only a small subset of the game, this evaluation round was important to gain a better perspective on the whole experience. Once again, due to continuous lockdown restrictions, the majority of the evaluation was done by remote participants. This time, a field test was also conducted with a participant.

Remote evaluation Overall gameplay feedback showed an increase in positive responses. There were only seven neutral responses which showed an improvement from the previous evaluation, which recorded a total of twenty-one neutral responses. The results obtained were consistent with the previous evaluation as $75 \%$ (7/8) participants 'Strongly Agreed' that the story was well integrated with the gameplay and was meaningful. All participants also agreed that the game integrated well with the surroundings. As noted above, increased knowledge of one's surroundings is another potential motivation for playing a location-based game.

Relating to the UI, there was also a noticeable improvement on 'The player sees the progress in the game and can compare the results' and 'The game provides clear goals'. This can be attributed to the addition of an overall map showing the fragments collected. In terms of usability, substantial improvements were observed, with $98.2 \%$ of participants choosing the "Agree" and "Strongly Agree" responses for most heuristics. The only non-agreeing response was given for "the game gives feedback on the players actions". 
All participants agreed on finding the game useful for University campus exploration, and would recommend the game to a someone who is new to the University.
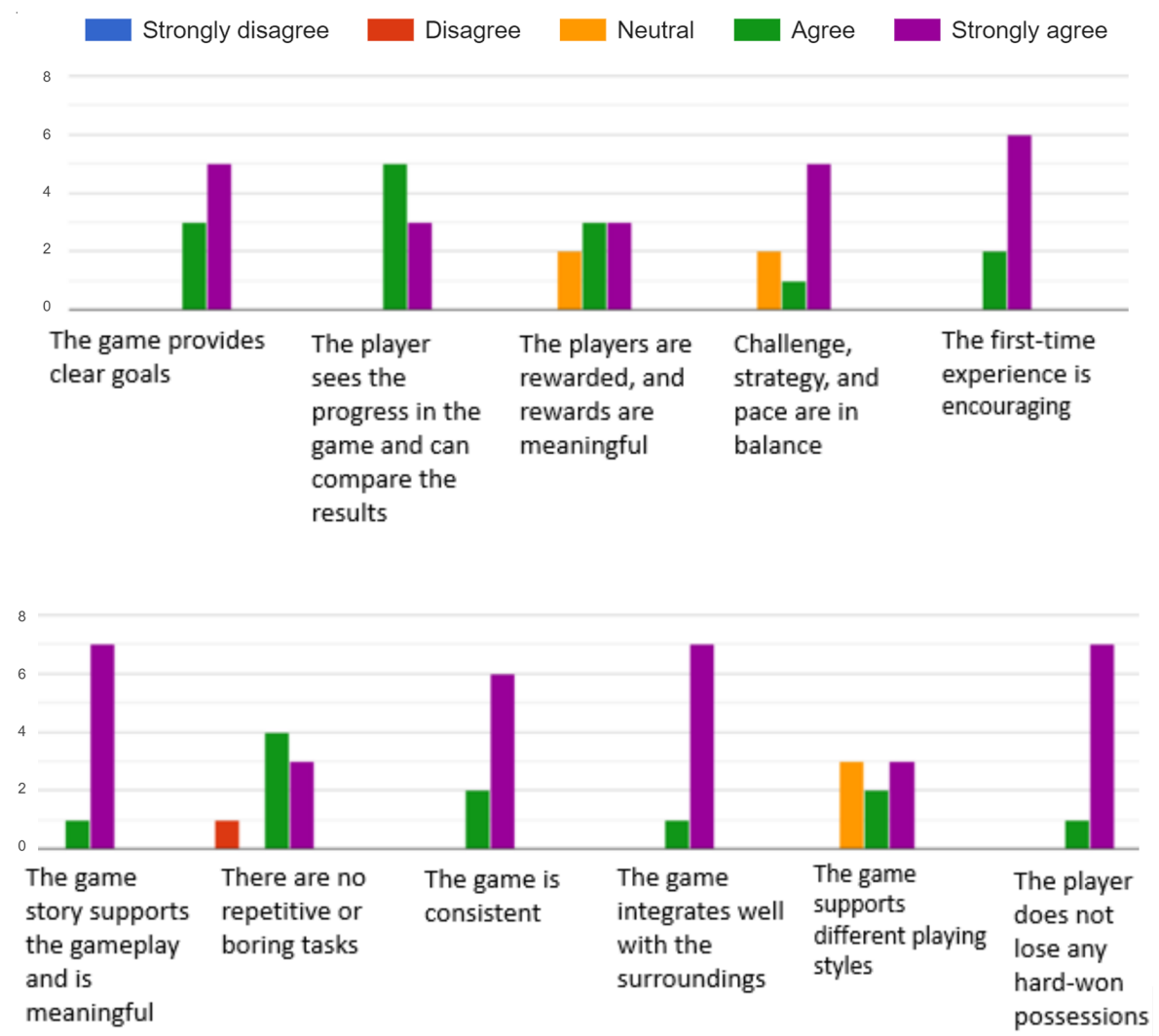

Fig. 3. Final gameplay evaluation results

Qualitative feedback In terms of additional features, a participant suggested adding a "description of what the different POI do, maybe even a bit of history to educate new students". The benefits of the game for exploration were acknowledged by two participants: "It was a good story, and a clear and helpful game", "Fun game to explore campus". Three participants in total explicitly mentioned the word "fun" when asked about their overall experience.

On-campus evaluation A field test was also conducted in which a single participant's behaviour was observed during the gameplay experience. The player 


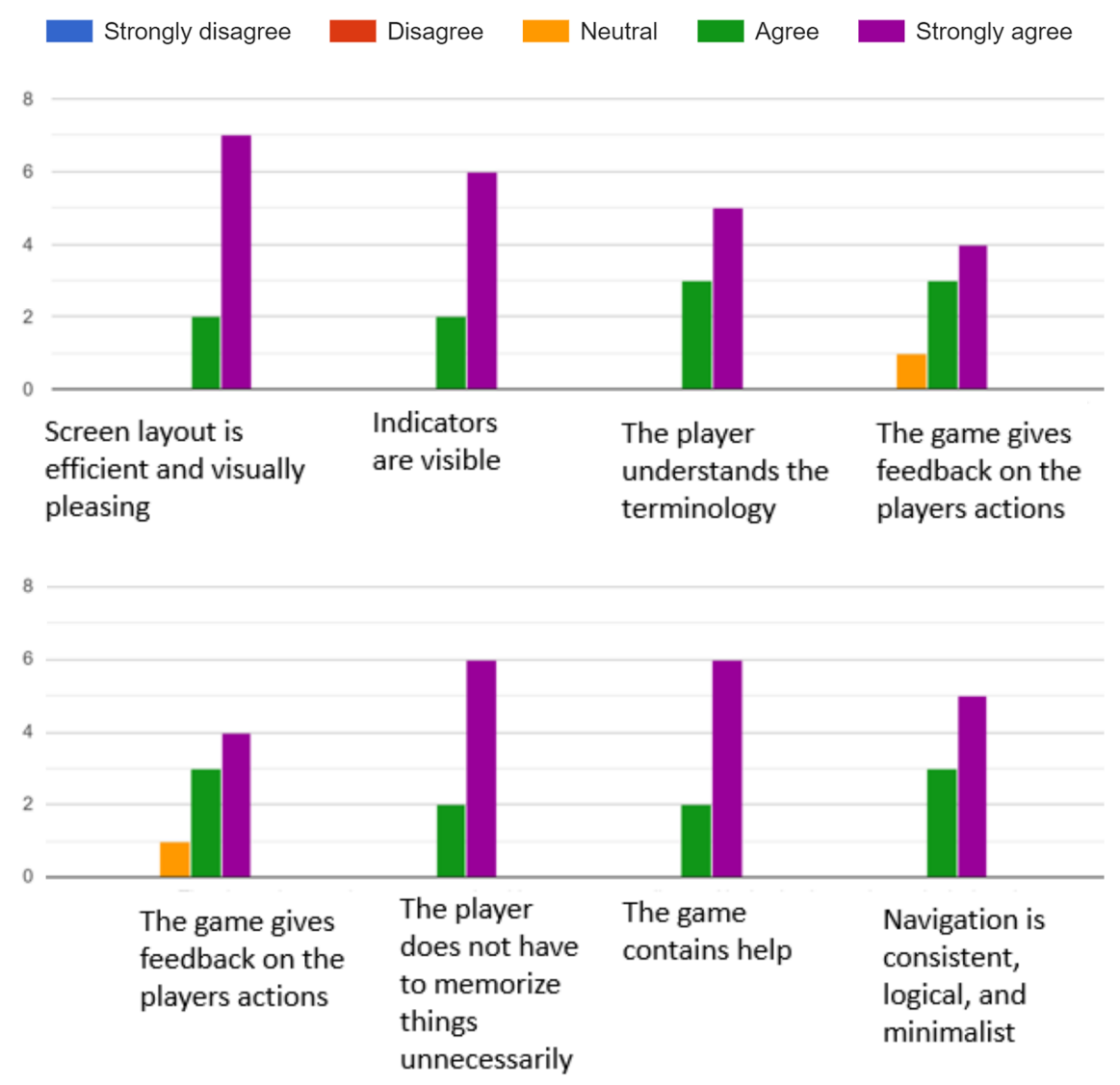

Fig. 4. Final usability evaluation results

was completely free to play at their own pace and no additional guidance was given unless needed. While progressing through the game, the participant showed active interest and investment in the story line, making remarks such as, "I think it might be him but not sure". The participant was able to find the solutions to all the riddles without requiring assistance. The player also had no issue navigating the map to find POIs. Lastly, the participant was asked if they felt that the tour was too long, to which they responded "Nope not at all".

\section{$5 \quad$ Limitations}

The game described here was developed and evaluated during the COVID-19 pandemic, during a period when significant restrictions were placed on people's movement. As a result, a relatively small number of participants were able to evaluate the software, and the evaluation carried out was largely desk-based 
in nature. This also meant that most of the evaluation was carried out using questionnaires, although the final, on-campus evaluation did involve observation, and the participant was able to play the game in situ.

The development of the game was also somewhat curtailed by lockdown restrictions, as visiting the campus and its various points of interest was not initially possible. However, Google Maps Street View was found to be an acceptable alternative, allowing the developer to get a sense of the locations despite being unable to visit them during the early stages of development.

\section{Conclusion}

The goal of this project was to design and develop a location-based game that encourages new students to explore the University of Glasgow's campus. Through iterative design and testing, the game was evaluated on two separate occasions, with a number of technical improvements in between. The initial concept and prototype were well received, but technical flaws were identified. These technical issues were addressed, and additional puzzles types were added in subsequent iterations. Furthermore, the map system was refined to better reflect the player's progress. The choice of Unity and Mapbox provided a solid foundation for the game to be built upon, allowing for straightforward remote testing through the use of mock location data, which was useful during the early stages of iterative development. The creation of a detective-style story that blended in with the University of Glasgow campus was also successful. We conclude, then, that a narrative location-based game is an effective means of encouraging students to explore their university campus.

If the project were repeated, the design process of the POI activities would be allocated more resources. Moreover, it is important to gather feedback from users during the design phase [12]: this project's early design stages could have

benefited from more end user involvement. Improvements to the game might include further diversifying the POI activities and the range of available rewards. The implementation of social features such as leaderboards and messaging might also be considered.

\section{References}

1. Bartle, R.A.: Designing virtual worlds. New Riders (2004)

2. Boticki, I., Hoic-Bozic, N., Budiscak, I.: A System Architecture for a Contextaware Blended Mobile Learning Environment. Journal of computing and information technology 17(2), 165-175 (Jun 2009). https://doi.org/10.2498/cit.1001187, https://hrcak.srce.hr/44856

3. Bunting, B.S., Hughes, J., Hetland, T.: The Player as Author: Exploring the Effects of Mobile Gaming and the Location-Aware Interface on Storytelling. Future Internet 4(1), 142-160 (Mar 2012). https://doi.org/10.3390/fi4010142, https://www.mdpi.com/1999-5903/4/1/142, number: 1 Publisher: Molecular Diversity Preservation International 
4. Bürgisser, B., Zünd, F., Pajarola, R., Sumner, R.W.: Campus Explorer: Facilitating Student Communities through Gaming. In: Proceedings of the International Conference on Game and Entertainment Technologies. pp. 169-176. IADIS, Madrid, Spain (Jul 2018), http://www.iadisportal.org/digital-library/campusexplorer-facilitating-student-communities-through-gaming

5. Carrigy, T., Naliuka, K., Paterson, N., Haahr, M.: Design and evaluation of player experience of a location-based mobile game. In: Proceedings of the 6th Nordic Conference on Human-Computer Interaction: Extending Boundaries. pp. 92-101. NordiCHI '10, Association for Computing Machinery, New York, NY, USA (Oct 2010). https://doi.org/10.1145/1868914.1868929, https://doi.org/10.1145/1868914.1868929

6. Chou, T.L., ChanLin, L.J.: Augmented Reality Smartphone Environment Orientation Application: A Case Study of the Fu-Jen University Mobile Campus Touring System. Procedia - Social and Behavioral Sciences 46, 410-416 (Jan 2012). https://doi.org/10.1016/j.sbspro.2012.05.132, https://www.sciencedirect.com/science/article/pii/S187704281201261X

7. Corti, K.: Games-based Learning: a serious business application. Tech. rep., PIXELearning Limited (2006)

8. Experience, W.L.i.R.B.U.: 10 Usability Heuristics for User Interface Design, https://www.nngroup.com/articles/ten-usability-heuristics/

9. Fitz-Walter, Z., Tjondronegoro, D., Wyeth, P.: Orientation Passport: using gamification to engage university students. In: Proceedings of the 23rd Australian Computer-Human Interaction Conference. pp. 122-125. OzCHI '11, Association for Computing Machinery, New York, NY, USA (Nov 2011). https://doi.org/10.1145/2071536.2071554, https://doi.org/10.1145/2071536.2071554

10. Fitz-Walter, Z., Tjondronegoro, D., Wyeth, P.: A gamified mobile application for engaging new students at university orientation. In: Proceedings of the 24th Australian Computer-Human Interaction Conference. pp. 138-141. OzCHI '12, Association for Computing Machinery, New York, NY, USA (Nov 2012). https://doi.org/10.1145/2414536.2414560, https://doi.org/10.1145/2414536.2414560

11. Forsyth, E.: AR U Feeling Appy?: Augmented Reality, Apps and Mobile Access to Local Studies Information. Australasian Public Libraries and Information Services (Sep 2011), https://search.informit.org/doi/abs/10.3316/ielapa.358381864604105

12. Fullerton, T.: Game Design Workshop. A K Peters/CRC Press, 0 edn. (Aug 2018). https://doi.org/10.1201/b22309, https://www.taylorfrancis.com/books/9781351597708

13. Furht, B.: Handbook of Augmented Reality. Springer Science \& Business Media (Aug 2011), google-Books-ID: fG8JUdrScsYC

14. Hwang, G.J., Chu, H.C., Lin, Y.S., Tsai, C.C.: A knowledge acquisition approach to developing Mindtools for organizing and sharing differentiating knowledge in a ubiquitous learning environment. Computers \& Education 57(1), 1368-1377 (Aug 2011). https://doi.org/10.1016/j.compedu.2010.12.013

15. Kjeldskov, J., Paay, J.: Augmenting the City with Fiction: Fictional Requirements for Mobile Guides. In: Proceedings of HCI in Mobile Guides, Mobile HCI 2007. p. 7. University of Lancaster, UK (2007)

16. Klante, P., Krösche, J., Ratt, D., Boll, S.: First-year students' paper chase: a mobile location-aware multimedia game. In: Proceedings of the 12th annual ACM international conference on Multimedia. pp. 934935. MULTIMEDIA '04, Association for Computing Machinery, New 
York, NY, USA (Oct 2004). https://doi.org/10.1145/1027527.1027740, https://doi.org/10.1145/1027527.1027740

17. Korhonen, H., Koivisto, E.M.I.: Playability heuristics for mobile games. In: Proceedings of the 8th conference on Human-computer interaction with mobile devices and services - MobileHCI '06. p. 9. ACM Press, Helsinki, Finland (2006). https://doi.org/10.1145/1152215.1152218, http://portal.acm.org/citation.cfm?doid $=1152215.1152218$

18. Laato, S., Pietarinen, T., Rauti, S., Laine, T.H.: Analysis of the Quality of Points of Interest in the Most Popular Location-based Games. In: Proceedings of the 20th International Conference on Computer Systems and Technologies. pp. 153160. ACM, Ruse Bulgaria (Jun 2019). https://doi.org/10.1145/3345252.3345286, https://dl.acm.org/doi/10.1145/3345252.3345286

19. Lynley, M.: With 500M downloads, Pokemon Go is coming to the Apple Watch TechCrunch, https://techcrunch.com/2016/09/07/pokemon-go-the-hottest-gameon-the-planet-is-coming-to-the-apple-watch/

20. Magerkurth, C., Cheok, A.D., Mandryk, R.L., Nilsen, T.: Pervasive games: bringing computer entertainment back to the real world. Computers in Entertainment 3(3), 4-4 (Jul 2005). https://doi.org/10.1145/1077246.1077257, https://dl.acm.org/doi/10.1145/1077246.1077257

21. Mapbox: https://mapbox.com/

22. Olli, S.: All the world's a botfighter stage: Notes on location-based multi-user gaming. In: Computer Games and Digital Cultures Conference Proceedings. Tampere University Press (June 2002), http://www.digra.org/wp-content/uploads/digitallibrary/05164.14477.pdf

23. Paavilainen, J., Korhonen, H., Alha, K., Stenros, J., Koskinen, E., Mayra, F.: The pokemon go experience: A location-based augmented reality mobile game goes mainstream. In: Proceedings of the 2017 CHI Conference on Human Factors in Computing Systems. pp. 2493-2498. CHI '17, Association for Computing Machinery, New York, NY, USA (May 2017). https://doi.org/10.1145/3025453.3025871, https://doi.org/10.1145/3025453.3025871

24. Paelke, V., Oppermann, L., Reimann, C.: Mobile Location-Based Gaming. In: Meng, L., Zipf, A., Winter, S. (eds.) Map-based Mobile Services: Design, Interaction and Usability, pp. 310-334. Lecture Notes in Geoinformation and Cartography, Springer, Berlin, Heidelberg (2008). https://doi.org/10.1007/978-3-540-371106, https://doi.org/10.1007/978-3-540-37110-6

25. Pérez-Sanagustín, M., Ramirez-Gonzalez, G., Hernández-Leo, D., Muñoz-Organero, M., Santos, P., Blat, J., Delgado Kloos, C.: Discovering the campus together: A mobile and computer-based learning experience. Journal of Network and Computer Applications 35(1), 176-188 (Jan 2012). https://doi.org/10.1016/j.jnca.2011.02.011, https://www.sciencedirect.com/science/article/pii/S108480451100049X

26. Schell, J.: The Art of Game Design: A book of lenses. CRC Press (2008)

27. Unity: https://unity.com/

28. Yee, N.: Motivations for play in online games. CyberPsychology \& Behavior 9(6), 772-775 (2006) 